\title{
Mixed Lineage Kinase Domain-Like Pseudokinase (MLKL) Gene Expression in Human Atherosclerosis with and without Type 2 Diabetes Mellitus
}

\author{
Amany Mohamed Kamal ${ }^{1}$, Samer Ahmed Sebak ${ }^{2}$ and Eman Fouad Sanad ${ }^{1 *}$ \\ ${ }^{1}$ Department of Biochemistry, Faculty of Pharmacy, Ain Shams University, Cairo, Egypt; \\ ${ }^{2}$ Department of Cardiology, Maadi Military Hospitals, Cairo, Egypt
}

Received 19 October 2020; accepted 25 December 2020; published online 9 June 2021

\begin{abstract}
Background: MLKL, one of the main downstream components of the necroptosis or programmed necrosis has recently been demonstrated in advanced atherosclerotic lesions. However, its precise role in the atherosclerosis pathogenesis still requires more elucidation. Our study was set to delineate both the changes in peripheral MLKL gene expression and its influence on disease severity in atherosclerotic patients with and without type 2 DM. Methods: The study involved 50 patients ( 20 non-diabetics and 30 diabetics) undergoing coronary artery bypass graft and 20 apparently healthy controls. Taqman RT-PCR was used to quantify MLKL mRNA expression levels, while ELISA was employed to estimate serum insulin and hSCRP levels. Results: Compared with the control group, MLKL gene was up regulated significantly in CVD $(p \leq 0.001)$. Higher MLKL expression was demonstrated in diabetic CVD group than non-diabetic group $(p<0.05)$. Correlation studies reported positive associations between MLKL and markers of dyslipidemia, inflammation, and insulin resistance. Multiple regression analysis revealed that FBG levels, hsCRP levels, and total WBCs count were significant predictors for MLKL levels. ROC showed a significant diagnostic value of MLKL for CVD. Moreover, regression analysis demonstrated that MLKL and hsCRP were independent predicting factors for the severity of CVD. Conclusion: MLKL is linked to hallmarks of atherosclerosis and could explain increased cardiovascular risk in diabetic patients. Thus, it can be a potential drug target for treatment of atherosclerotic patients. DOI: 10.52547/ibj.25.4.265
\end{abstract}

Keywords: Atherosclerosis, Diabetes mellitus, Inflammation, Insulin resistance, Necroptosis

Corresponding Author: Eman Fouad Sanad

Department of Biochemistry, Faculty of Pharmacy, Ain Shams University, Cairo, Egypt; Tel.: (+20-100) 1645353; Fax: (+20-2) 24051107;

E-mail: dr.emansanad@pharma.asu.edu.eg

\section{INTRODUCTION}

A therosclerosis, an inflammatory disease, is the prime reason for the majority of CVDs, the central cause of global deaths ${ }^{[1]}$. Type 2 DM, mainly characterized by hyperglycemia due to insulin resistance, is the most common metabolic disease worldwide and is increasing drastically in developing countries $^{[2]}$. Diabetes is deeply implicated in the pathogenesis of atherosclerosis and increasing the risk of CVD by up to three folds ${ }^{[3]}$.

Beyond the clear role of smooth muscle and endothelial cells in atherogenesis, many immunologic components were identified as crucial mediators in

List of Abbreviations:

AUC, area under curve; BMI, body mass index; CAD, coronary artery diseases; CVD, cardiovascular diseases; DM, diabetes mellitus; GAPDH, glyceraldehyde-3-phosphate dehydrogenase; HbA1c\%, glycated hemoglobin; HDL-C, high-density lipoprotein cholesterol; HOMA-IR, homeostasis model assessment of insulin resistance; hsCRP, high sensitivity C-reactive protein; LDL-C, low-density lipoprotein cholesterol; MLKL, mixed lineage kinase domain-like pseudokinase; QUICKI, quantitative insulin sensitivity check index; QUICKI, quantitative insulin sensitivity check index; RIPK, receptor-interacting protein kinase; ROC, Receiver operating characteristic curve; WBCs, white blood cells 
atherosclerosis in which the inflammatory process is a pivotal regulator ${ }^{[4]}$. The inflammatory response could be speculated by many circulating inflammatory biomarkers such as hsCRP, a poor prognostic marker in atherosclerosis ${ }^{[5]}$. Inflammation is closely related to cell death as many of the receptors that drive inflammatory cytokine expression can also induce the cell death $^{[6]}$.

Activated immune cells not only mediate fibrous cap degradation and subsequent plaque rupture but also mediate apoptotic cell death in atherosclerotic plaques $^{[7]}$. The concept of cells equipped with an internal self-destruction mechanism was first proposed in 1965, highlighting the essential role of programmed cell death in many inflammatory-driven diseases ${ }^{[8]}$. Since then, the magnitude and the mechanism of cell death have extensively been studied. Nowadays, apoptosis, necrosis, and necroptosis are the three well characterized and extensively studied cell death pathways $^{[9]}$.

Necroptosis or programmed necrosis is triggered by many signals such as death receptor ligands. RIPK 1 and 3 as well as MLKL, which constitute the regulatory necrosome complex, are the central regulators of necroptosis ${ }^{[10]}$. The first member of necroptosis-induced death receptors, RIPK1, was first described by Holler et al. ${ }^{[11]}$ in 2000 . However, the term necroptosis was introduced by Degterev and coworkers $^{[12]}$ in 2005. The main players of the necroptotic pathway are RIPK3 and MLKL ${ }^{[13]}$. The latter was first described by Sun et al. ${ }^{[14]}$ in 2012 as a RIP3 substrate in the necroptotic pathway. Although necroptosis can protect cells against pathogens, its regulation impairment has been recognized as an emerging important pathway in many autoimmune and/or inflammatory diseases ${ }^{[6]}$ as a consequence of immunogenic cellular content release, such as cytokines and damage-associated molecular patterns to initiate inflammatory responses ${ }^{[13]}$.

The activation of RIPK1/3 by death receptors or tolllike receptors induces necrosome formation, which in turn phosphorylates MLKL, the necroptotic executioner $^{[15]}$. This phosphorylation induces MLKL oligomerization and bind to phosphatidylinositol phosphates of the cell membrane with subsequent formation of a pore-forming complex. These events lead to rapid necrotic membrane disruption ${ }^{[16]}$ and the release of potential damage-associated molecular patterns $^{[17]}$. An alternative suggested mechanism is the translocation of phosphorylated MLKL to the plasma membrane with calcium or sodium influx that trigger the rupture of necrotic membrane as a result of increased osmotic pressure ${ }^{[18]}$. Although RIPK1 is fundamental for necroptosis, recent studies have proven that MLKL can directly induce necroptosis ${ }^{[13]}$.

Necroptotic MLKL signaling has been reported in different inflammatory diseases, such as tumor necrosis factor-induced shock ${ }^{[19]}$, obesity ${ }^{[20]}$, and ischemiareperfusion injuries ${ }^{[21]}$. Since MLKL is an essential element in necroptosis, it may be considered as a promising target for restraining necroptosis and associated inflammation, the major hallmark of atherosclerosis. Although phosphorylated MLKL has been demonstrated in advanced atherosclerotic lesions $^{[22]}$, and its functional knockdown showed a significant decrease in plaque necrotic core ${ }^{[23]}$, the exact relations between MLKL and key processes of atherogenesis along with the influence of DM are still unclear. Accordingly, we aimed to investigate the expression pattern changes of the human MLKL gene in circulating leukocytes and their link to atherosclerosis severity. Moreover, the association of MLKL with inflammatory response and insulin resistance in addition to other risk factors in atherosclerosis accompanied by DM were assessed.

\section{MATERIALS AND METHODS}

\section{Sample size calculation}

Using PASS 13 for sample size calculation and data from previous studies ${ }^{[22,24]}$, a sample size of 20 patients per group achieved $81 \%$ power to detect differences among the MLKL means versus the alternative of equal means using an $\mathrm{F}$ test with a 0.05 significance level.

\section{Subjects}

From May 2018 to August 2019, a total of 50 patients (29 males and 21 females) undergoing coronary artery bypass grafting were selected from Maadi Military Hospitals, Egypt. Using angiography, the CAD severity was evaluated in patients according to the number of atherosclerotic blood vessels. Based on patients' history and postprandial and fasting plasma glucose levels, the patients' group was divided into non-diabetic (20 CVD/non-diabetic patients; 12 males and 8 females) and diabetic (30 CVD/diabetic patients; 17 males and 13 females) subgroups. The control group was composed of 20 (13 males and 7 females) age- and sex-matched healthy volunteers. Subjects with acute coronary syndrome, type 1 DM, kidney diseases, liver diseases, malignancy, acute and chronic inflammatory diseases, or autoimmune disorders were excluded.

\section{Blood samples}

Fasting peripheral blood samples were obtained from 
controls and CVD subjects before the surgical operation. Blood samples were divided into three aliquots for whole blood, plasma, and serum preparation. Serum was used for the assay of lipids parameters, insulin, and hsCRP. Whole blood was used for the determination of $\mathrm{HbA} 1 \mathrm{c} \%$, full blood count, and total RNA extraction, while plasma was used for the FBG assay.

\section{Biochemical analysis}

Sysmex ${ }^{\circledR}$ XT 2000i autoanalyzer (Japan) was used to determine full blood count, whereas Cobas® 8000 Modular automated analyzer (Roche Diagnostics, Germany) was employed to determine the levels of FBG, total cholesterol, triglycerides, HDL-C, and LDL-C. The Bio-Rad VARIANT II Turbo Hemoglobin Testing System (Bio-Rad Laboratories, Hercules, CA, USA) was utilized to determine $\mathrm{HbA} 1 \mathrm{c} \%$ levels. Serum hsCRP and fasting insulin were measured by ELISA technique using MyBioSource ELISA kits (USA). The HOMA-IR and QUICKI were calculated as follows: HOMA-IR $=$ fasting insulin $(\mu \mathrm{U} / \mathrm{mL}) \times$ FBG $(\mathrm{mg} / \mathrm{dL}) / 405^{[25]}$ and QUICKI $=1 /[\log ($ fasting insulin $)+\log (\mathrm{FBG})]^{[26]}$, respectively.

\section{RNA isolation and quantitative Taqman RT-PCR}

Total RNA was extracted and purified using QIAamp RNA Blood Mini extraction kit (Qiagen, Germany) as the manufacturer's protocol. After the determination of RNA concentration and purity using DeNovix Donating Platinum Edition DS-11 (Wilmington, Delaware, USA), a total RNA of $500 \mathrm{ng}$ was reversely transcribed to cDNA by High-Capacity cDNA Reverse Transcription Kit with RNase Inhibitor (catalog number: 4374967) supplied by Applied Biosystems (USA) using Biometra TProfessional Standard Thermocycler (Biometra, Germany). Taqman RT-PCR was carried out on Rotor-gene Q (Qiagen, Germany) using Taqman® Universal Master Mix II (Applied Biosystems, USA). Human MLKL and GAPDH predesigned ready-to-use primers and probe Taqman® assays were supplied by Applied Biosystems (Assay IDs: Hs04188505_m1 and Hs02786624_g1, respectively). Each Taqman $®$ gene expression assay contained $18 \mathrm{uM}$ of corresponding forward and reverse primers and $5 \mathrm{uM}$ of specific probe in $20 \times$ format. cDNA template $(50 \mathrm{ng})$, Taqman ${ }^{\circledR}$ gene expression assay $(1 \mu \mathrm{L})$, and Taqman ${ }^{\circledR}$ universal master mix (10 $\mu \mathrm{L})$ were used to perform Taqman RT-PCR. The used reaction protocol involved uracil-N-glycosylase activation at $50{ }^{\circ} \mathrm{C}$ for $2 \mathrm{~min}$, then polymerase activation at $95{ }^{\circ} \mathrm{C}$ for $10 \mathrm{~min}$, followed by 40 amplification cycles (at $95^{\circ} \mathrm{C}$ for $15 \mathrm{~s}$ and at $60^{\circ} \mathrm{C}$ for $1 \mathrm{~min})$. Each experiment included a negative control.
The relative MLKL gene expression levels were normalized and analyzed by the $2^{-\Delta \Delta \mathrm{Ct}}$ method where $\Delta \Delta \mathrm{Ct}=\left(\mathrm{Ct}_{\mathrm{MLKL}}-\mathrm{Ct}_{\mathrm{GAPDH}}\right)$ sample - $\left(\mathrm{Ct}_{\mathrm{MLKL}}-\mathrm{Ct}_{\mathrm{GAPDH}}\right)$ control $^{[27]}$.

\section{Statistical analysis}

The IBM SPSS statistics (V.23, USA) was used to perform all the statistical analyses. Nominal data were represented as numbers (percentages) and performed by Chi-square test. Numerical data were represented as mean \pm SEM. Student's t-test or Mann-Whitney U test was used to compare two independent mean groups for parametric and nonparametric variables, respectively. More than two groups were compared by one-way ANOVA with a post-hoc Tukey test or Kruskal-Wallis test for parametric and nonparametric variables, respectively. Correlations were estimated by Pearson or Ranked Spearman tests. ROC curve analysis was performed to evaluate the diagnostic value of MLKL gene expression. Finally, multiple regression analysis was conducted to investigate parameters associated with MLKL expression and to assess predictors that contribute to CAD severity. $p$ values of 0.05 or less were considered of a statistical significance.

\section{Ethical statement}

The above-mentioned sampling protocol was approved by the Ethical Committee of Faculty of Pharmacy, Ain Shams University, Egypt (ethical code: 2/2018-52). The study followed the regulations and recommendations of the Declaration of Helsinki ${ }^{[28]}$. A written consent indicating the use of blood samples for research purposes and the aim of the study was obtained from each participant.

\section{RESULTS}

\section{Demographic and clinicopathological data of the studied groups}

Table 1 summarizes the subjects' demographic and clinicopathological data. No statistical difference was observed between the control and CVD/non-diabetic and CVD/diabetic group regarding age, gender, BMI, and monocyte and eosinophil percentages, while a statistical difference was reported between the studied groups with respect to the rest of the measured parameters. Comparing with non-diabetic group, CVD/diabetic group showed significantly the higher levels of lipid profile parameters, including triglyceride, total cholesterol, LDL-C, cardiovascular risk ratios, $\mathrm{FBG}, \mathrm{HbA} 1 \mathrm{c} \%$, HOMA-IR index, and hsCRP, as well as significantly lower levels of red blood cells count and QUICKI index. 
Table 1. Demographic data, clinicopathological parameters, and MLKL gene expression levels of the studied groups

\begin{tabular}{|c|c|c|c|}
\hline Data & $\begin{array}{c}\text { Control group } \\
(n=20)\end{array}$ & $\begin{array}{l}\text { CVD/non-diabetic } \\
\text { group }(n=20)\end{array}$ & $\begin{array}{l}\text { CVD/diabetic } \\
\operatorname{group}(n=30)\end{array}$ \\
\hline Age (years) & $51.95 \pm 0.60$ & $54.65 \pm 1.18$ & $54.90 \pm 0.84$ \\
\hline Gender (Males/Females) & $13 / 7$ & $12 / 8$ & $17 / 13$ \\
\hline $\operatorname{BMI}\left(\mathrm{Kg} / \mathrm{m}^{2}\right)$ & $25.84 \pm 0.17$ & $26.41 \pm 0.53$ & $27.02 \pm 0.56$ \\
\hline Hypertension (n, \%) & $0(0 \%)$ & $14(70.0 \%)^{\mathrm{a}}$ & $22(73.3 \%)^{\mathrm{a}}$ \\
\hline Current smoking $(\mathrm{n}, \%)$ & $2(10 \%)$ & $10(50.0 \%)^{\mathrm{a}^{*}}$ & $17(56.7 \%)^{\mathrm{a}^{*}}$ \\
\hline $\mathrm{TG}(\mathrm{mg} / \mathrm{dL})$ & $84.56 \pm 4.83$ & $125.30 \pm 7.74^{\mathrm{a}^{*}}$ & $165.33 \pm 9.78^{\mathrm{a}, \mathrm{b} \#}$ \\
\hline $\mathrm{TC}(\mathrm{mg} / \mathrm{dL})$ & $148.94 \pm 3.08$ & $171.50 \pm 4.18^{\mathrm{a}^{*}}$ & $195.27 \pm 5.22^{\mathrm{a}, \mathrm{b \#}}$ \\
\hline HDL-C (mg/dL) & $53.06 \pm 1.42$ & $36.75 \pm 1.69^{\mathrm{a}}$ & $32.30 \pm 1.03^{\mathrm{a}}$ \\
\hline LDL-C(mg/dL) & $78.94 \pm 3.13$ & $109.60 \pm 3.37^{\mathrm{a}}$ & $129.85 \pm 4.49^{\mathrm{a}, \mathrm{b} \#}$ \\
\hline $\mathrm{TC} / \mathrm{HDL}$ & $2.83 \pm 0.09$ & $4.82 \pm 0.20^{\mathrm{a}}$ & $6.23 \pm 0.26^{\mathrm{a}, \mathrm{b}}$ \\
\hline LDL/HDL & $1.51 \pm 0.08$ & $3.10 \pm 0.17^{\mathrm{a}}$ & $4.17 \pm 0.21^{\mathrm{a}, \mathrm{b}}$ \\
\hline $\mathrm{FBG}(\mathrm{mg} / \mathrm{dL})$ & $86.40 \pm 1.37$ & $98.41 \pm 2.08$ & $190.33 \pm 8.19^{\mathrm{a}, \mathrm{b}}$ \\
\hline $\mathrm{HbA}_{1 \mathrm{c}}(\%)$ & $5.11 \pm 0.07$ & $5.72 \pm 0.05$ & $8.83 \pm 0.26^{\mathrm{a}, \mathrm{b}}$ \\
\hline Insulin $(\mu \mathrm{IU} / \mathrm{mL})^{\mathbb{I}}$ & $3.15 \pm 0.26$ & $9.86 \pm 1.86^{\mathrm{a} \#}$ & $8.61 \pm 1.12^{\mathrm{a} \#}$ \\
\hline QUICKI & $0.42 \pm 0.01$ & $0.36 \pm 0.01^{\mathrm{a}}$ & $0.31 \pm 0.02^{\mathrm{a}, \mathrm{b} \#}$ \\
\hline HOMA-IR ${ }^{\mathbb{I}}$ & $0.68 \pm 0.06$ & $2.38 \pm 0.46^{\mathrm{a}}$ & $4.23 \pm 0.67^{\mathrm{a}, \mathrm{b} \#}$ \\
\hline hsCRP $(\mathrm{mg} / \mathrm{L})^{\mathbb{I}}$ & $0.76 \pm 0.11$ & $5.55 \pm 0.83^{\mathrm{a}}$ & $11.34 \pm 1.53^{\mathrm{a}, \mathrm{b}^{*}}$ \\
\hline $\operatorname{RBCs}\left(10^{6}\right.$ cells $\left./ \mathrm{cm}^{3}\right)$ & $5.07 \pm 0.12$ & $4.38 \pm 0.11^{\mathrm{a}}$ & $4.71 \pm 0.10^{\mathrm{a}, \mathrm{b} \#}$ \\
\hline WBCs $\left(10^{3}\right.$ cell $\left./ \mathrm{cm}^{3}\right)$ & $5.57 \pm 0.23$ & $7.48 \pm 0.40^{\mathrm{a}^{*}}$ & $8.12 \pm 0.50^{\mathrm{a}}$ \\
\hline Neutrophils (\% of WBCs) & $51.75 \pm 1.17$ & $62.40 \pm 2.54^{\mathrm{a} \#}$ & $61.33 \pm 2.03^{\mathrm{a} \#}$ \\
\hline Lymphocytes (\% of WBCs) & $37.44 \pm 1.00$ & $27.00 \pm 2.08^{\mathrm{a} \#}$ & $29.03 \pm 1.92^{\mathrm{a} \#}$ \\
\hline Monocytes (\% of WBCs) & $7.22 \pm 0.33$ & $7.75 \pm 0.57$ & $7.10 \pm 0.30$ \\
\hline Eosinophils (\% of WBCs) & $2.56 \pm 0.27$ & $2.70 \pm 0.33$ & $2.34 \pm 0.25$ \\
\hline Basophils (\% of WBCs) & $0.78 \pm 0.18$ & $0.15 \pm 0.08^{\mathrm{a}}$ & $0.19 \pm 0.07^{\mathrm{a}}$ \\
\hline mRNA MKLK levels (fold expression) ${ }^{\mathrm{I}}$ & $1.00 \pm 0.01$ & $4.28 \pm 0.30^{\mathrm{a}}$ & $7.01 \pm 0.70^{\mathrm{a}, \mathrm{b}^{*}}$ \\
\hline
\end{tabular}

Data are presented as mean \pm SEM or numbers of patient (percentages); ${ }^{\mathbb{T}}$ Variables analyzed by Kruskal Wallis test. ${ }^{\mathrm{a}}$ considered statistically significant from the control group at $p \leq 0.001$; ${ }^{\mathrm{b}}$ considered statistically significant from CVD/non-diabetic group at $p \leq$ 0.001 ; " statistically significant at $p \leq 0.01$; "statistically significant at $p \leq 0.05$; RBCs, red blood cells; TC, total cholesterol; TG, triglycerides

MLKL gene expression and its diagnostic value in the studied groups

As shown in Table 1 and Figure 1, MLKL gene expression was statistically elevated in CVD subjects than control subjects at $p<0.0001$. Moreover, MLKL expression was significantly higher in CVD/diabetic group $(7.01 \pm 0.70$ folds) than CVD/non-diabetic group (4.28 \pm 0.30 folds) at $p<0.05$. Besides, statistical analysis of MLKL gene expression levels regarding risk factors, including age, gender, BMI, hypertension, smoking, and hsCRP levels revealed a significant overexpression in patients with BMI $\geq 25 \mathrm{~kg} / \mathrm{m}^{2}$ compared to those with BMI $<25 \mathrm{~kg} / \mathrm{m}^{2}(7.07 \pm 0.61$ versus $4.07 \pm 0.55, p=0.001$; Fig. 2). There was also a significantly higher expression in patients having hsCRP levels $\geq 3 \mathrm{mg} / \mathrm{L}$ compared to patients having hsCRP levels $<3 \mathrm{mg} / \mathrm{L}(6.44 \pm 0.54$ versus $3.53 \pm 0.40$, $p=0.008)$. Regression analysis of parameters affecting
MLKL gene expression indicated that FBG, hsCRP, total WBCs count, and BMI were positive independent predictors for MLKL gene expression levels $(\beta=$ $0.468,0.259,0.299$, and 0.283 at $p<0.05$, respectively), as depicted in Table 2 , highlighting the possible role of these parameters in regulating MLKL expression. We also evaluated the diagnostic value of MLKL using ROC analysis, where MLKL showed an excellent diagnostic value for discrimination between CVD patients and controls (AUC $=0.93,95 \% \mathrm{CI}$ : $0.87-0.99$, sensitivity $=92 \%$, and specificity $=95 \%$ for cut-off value >1.16; Fig. 3A). However, ROC analysis for discrimination between $\mathrm{CVD} /$ diabetic patients and CVD/non-diabetic patients showed a moderate diagnostic value (AUC $=0.71,95 \%$ CI: $0.56-0.85$, sensitivity $60 \%$, specificity $=75 \%$ for a cut-off criterion $>4.465$; Fig. $3 \mathrm{~B}$ ). 


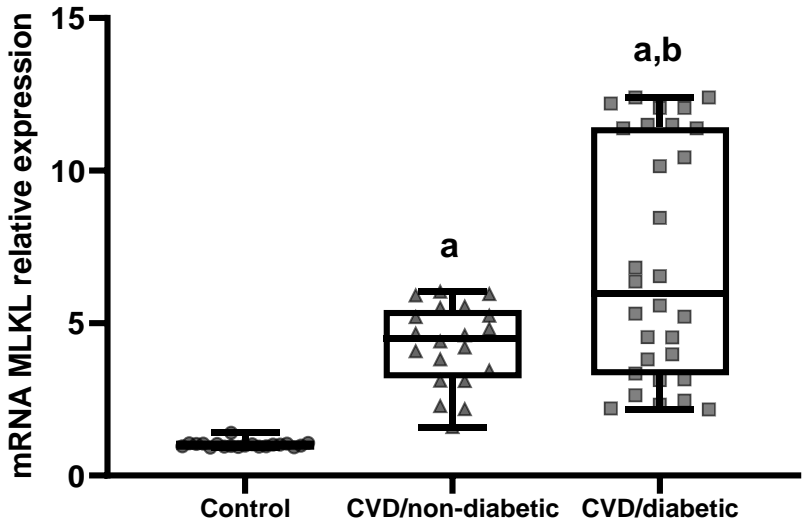

Fig. 1. Scatterplot illustrating MLKL relative expression levels in the studied groups. Groups are compared using Kruskal Wallis test. ${ }^{\text {a }}$ significantly different from the control group at $p<$ 0.001 ; ${ }^{b}$ significantly different from $\mathrm{CVD} /$ non-diabetic group at $p$ $<0.05$.

Correlations between MLKL gene expression and other demographic and clinicopathological parameters

As illustrated in Figure 4, MLKL gene expression showed positive correlations with total cholesterol, LDL-C, total cholesterol/HDL-C ratio, and LDLC/HDL-C ratio at $p<0.01(\mathrm{r}=0.393,0.579,0.424$, and 0.493 , respectively) and negative association with HDL-C $(\mathrm{r}=-0.296$, at $p<0.05)$. Moreover, MLKL gene expression levels showed positive relationship with insulin, glucose, HbA1c\%, HOMA-IR index, hsCRP, and WBCs count at $p<0.01$ and also displayed negative association with QUICKI index.

\section{Multivariate regression analysis for the CAD severity}

Concerning the severity of CAD, we found that MLKL gene expression levels were elevated in 22 patients having four atherosclerotic arteries as compared to its levels in 26 patients having three atherosclerotic arteries $(8.23 \pm 0.80$ versus $4.20 \pm 0.26$, at $p<0.001)$. To explore the possible variables associated with CAD severity, a multiple regression analysis utilizing the affected arteries number as a dependent parameter was performed. Three models were established by age, gender, BMI, DM, current smoking, hypertension, hsCRP, and MLKL gene expression as independent parameters. Patients' demographic data (age and gender) and MLKL expression levels were included in Model 1, while Model 2 includes atherosclerosis classical risk factors in addition to Model 1. In Model 3, we included hsCRP as an independent variable in addition to Model 2. As summarized in Table 3, both hsCRP and MLKL gene expression levels were independent predicting factors for CAD severity in Model 3 ( $\beta=0.360$ and 0.438 , at $p<0.05$, respectively).

\section{DISCUSSION}

When the tight balance between cell proliferation and death is disrupted, pathological events, including major CVD as atherosclerosis, occur ${ }^{[6]}$. DM increases the risk of CVD by two to three folds ${ }^{[3]}$ as a result of insulin resistance and other associated processes of dyslipidemia, inflammation, and cell death $^{[29,30]}$.

Apart from apoptosis and necrosis, necroptosis or programmed necrosis is a novel proinflammatory type of cell death that has recently been demonstrated as a critical player in cancer and several inflammatory diseases, including atherosclerosis ${ }^{[10,31]}$. Necroptosis activation leads to the phosphorylation of MLKL and subsequent cell lysis ${ }^{[16]}$. However, phosphorylated
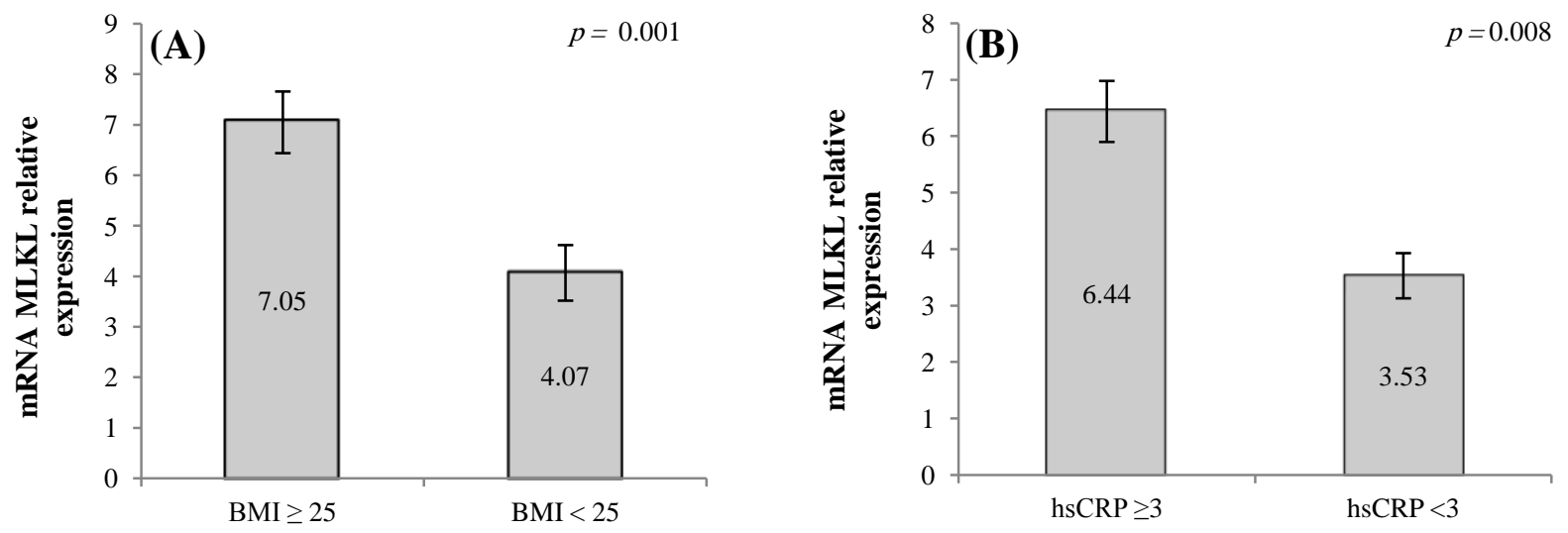

Fig. 2. MLKL gene expression levels with respect to (A) BMI $\geq 25$ and $<25 \mathrm{~kg} / \mathrm{m}^{2}$ and (B) serum hsCRP levels $\geq 3$ and $<3 \mathrm{mg} / \mathrm{L}$. Data are expressed as mean \pm SEM. Groups are compared using Mann-Whitney U test. 
Table 2. Multivariate regression analysis for predicting factors affecting mRNA levels of MLKL

\begin{tabular}{lccccc}
\hline \multirow{2}{*}{ Parameters } & \multicolumn{2}{c}{ Multivariate full regression } & & \multicolumn{2}{c}{ Multivariate stepwise regression } \\
\cline { 2 - 3 } \cline { 5 - 6 } & $\boldsymbol{B}$ & $\boldsymbol{p}$ & & $\boldsymbol{\beta}$ & $\boldsymbol{p}$ \\
\hline Age & 0.107 & 0.271 & & $\ldots \ldots$ & $\ldots \ldots$ \\
Gender & -0.070 & 0.383 & & $\ldots \ldots$ & $\ldots \ldots$. \\
BMI & 0.244 & $0.009^{*}$ & & 0.283 & $0.001^{* *}$ \\
Hypertension & 0.032 & 0.699 & & $\ldots \ldots$ & $\ldots \ldots$ \\
Current smoking & 0.134 & 0.156 & & $\ldots \ldots$ & $\ldots \ldots$ \\
HDL-C & -0.123 & 0.160 & & $\ldots \ldots$ & $\ldots \ldots$ \\
LDL-C & 0.045 & 0.598 & & $\ldots \ldots$ & $\ldots \ldots$. \\
hsCRP & 0.218 & $0.031^{*}$ & & 0.259 & $0.006^{* *}$ \\
Total WBC count & 0.222 & $0.022^{*}$ & & 0.299 & $0.001^{* *}$ \\
FBG & 0.424 & $<0.001^{* *}$ & & 0.468 & $<0.001^{* *}$ \\
Insulin & 0.204 & $0.025^{*}$ & & $\ldots \ldots$. & $\ldots \ldots \ldots$ \\
\hline
\end{tabular}

$\mathrm{R}^{2}$ for multivariate full regression and stepwise regression models for dependent variables were $79.2 \%$ and $72.1 \%$ respectively. ${ }^{*}$ statistically significant at $p \leq 0.05 ;{ }^{* *}$ statistically significant at $p \leq 0.01$

MLKL has lately been detected in advanced atherosclerotic lesions ${ }^{[23]}$ and diabetic mouse models ${ }^{[20]}$; its certain function in atherogenesis with the influence of diabetes needs more elucidation. Therefore, in this study we evaluated the alterations MLKL gene expression levels, together with its association with atherosclerosis-related hallmarks as well as disease severity in CVD patients.

The current study showed that MLKL gene expression levels significantly increased in both CVD groups when compared to the controls. Accumulating animal studies have proved that necroptosis is involved in the pathogenesis of CVD, e.g. acute coronary syndrome, abdominal aortic aneurysms, and atherosclerosis $^{[32,33]}$. However, the number of human studies in this field is still limited. Lin et al $^{[33]}$ reported elevated RIP3 within necroptotic cells of advanced atherosclerotic lesions in murine models of atherosclerosis. Subsequently, Karunakaran et al. ${ }^{[22]}$ reported elevated RIP3, MLKL, and phosphorylated MLKL in advanced human carotid atheroma. Necroptosis inhibition in the vasculature has been proven to have a protective outcome ${ }^{[31]}$, and hence, necroptosis is probably a novel promising therapeutic target to halt the atherogenesis. Additionally, MLKL gene expression was significantly elevated in CVD/diabetics than non-diabetics. To our best knowledge, this is the first work reporting circulating MLKL gene expression in human atherosclerotic diabetic patients. The elevated MLKL expression in diabetic patients could be attributed to sustained hyperglycemia, which is prevalent in diabetics and causes the production of excessive amounts of intracellular reactive oxygen species that potentiates systemic oxidative stress accelerating both apoptotic and proinflammatory processes ${ }^{[34]}$. Moreover, downstream necroptotic pathways include the production of advanced glycation end products and oxygen free radicals, depending on glycolysis. This evidence might explain the link between increased intracellular glucose and necroptosis induction ${ }^{[35]}$. Such relation is supported by a positive correlation

ROC curve CVD group Vs Control group

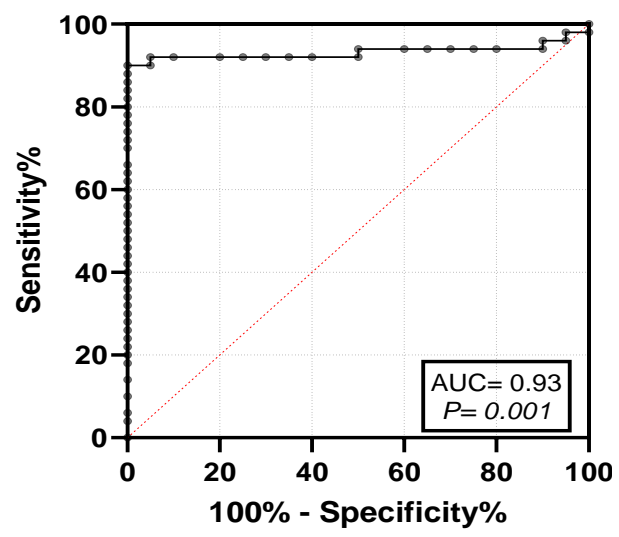

ROC curve: CVD/diabetic group Vs CVD/non-diabetic group

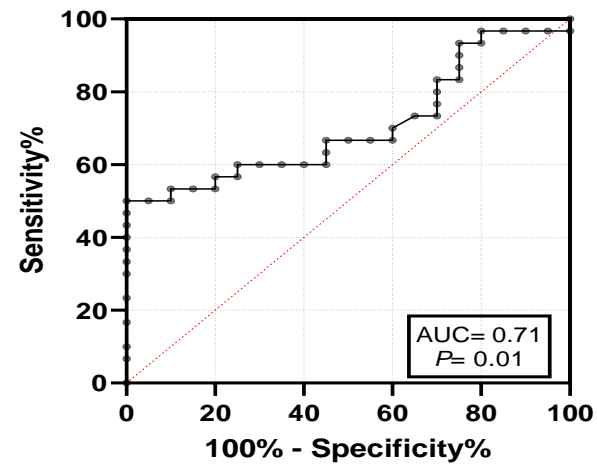

Fig. 3. ROC curve analysis for the diagnostic value of MLKL expression. 
between MLKL mRNA levels and $\mathrm{HbA} 1 \mathrm{c} \%$, a precursor for hemoglobin- advanced glycation end products $^{[36]}$.

In our study, diabetic and non-diabetic CVD patients showed an obvious insulin resistance manifested by elevated serum insulin and increased HOMA-IR index. This result complies with that of Karrowni et al. ${ }^{[37]}$ who reported elevated HOMA-IR index in CVD nondiabetic patients and could be ascribed to chronic subclinical inflammation, a prevalent risk factor for atherosclerosis. It has also been suggested that hsCRP could be an independent predictor of insulin resistance ${ }^{[38]}$. With regard to diabetes and its associated metabolic disturbance, correlation analysis demonstrated that MLKL gene expression had significant positive correlations with FBG, insulin, and HOMA-IR index and negative correlation with QUICKI index. Moreover, multivariate regression analysis identified FBG as a positive independent predictor for MLKL gene expression. This finding may approve the study of $\mathrm{Xu}$ and his colleges ${ }^{[20]}$ who revealed that hepatic MLKL could impair insulin
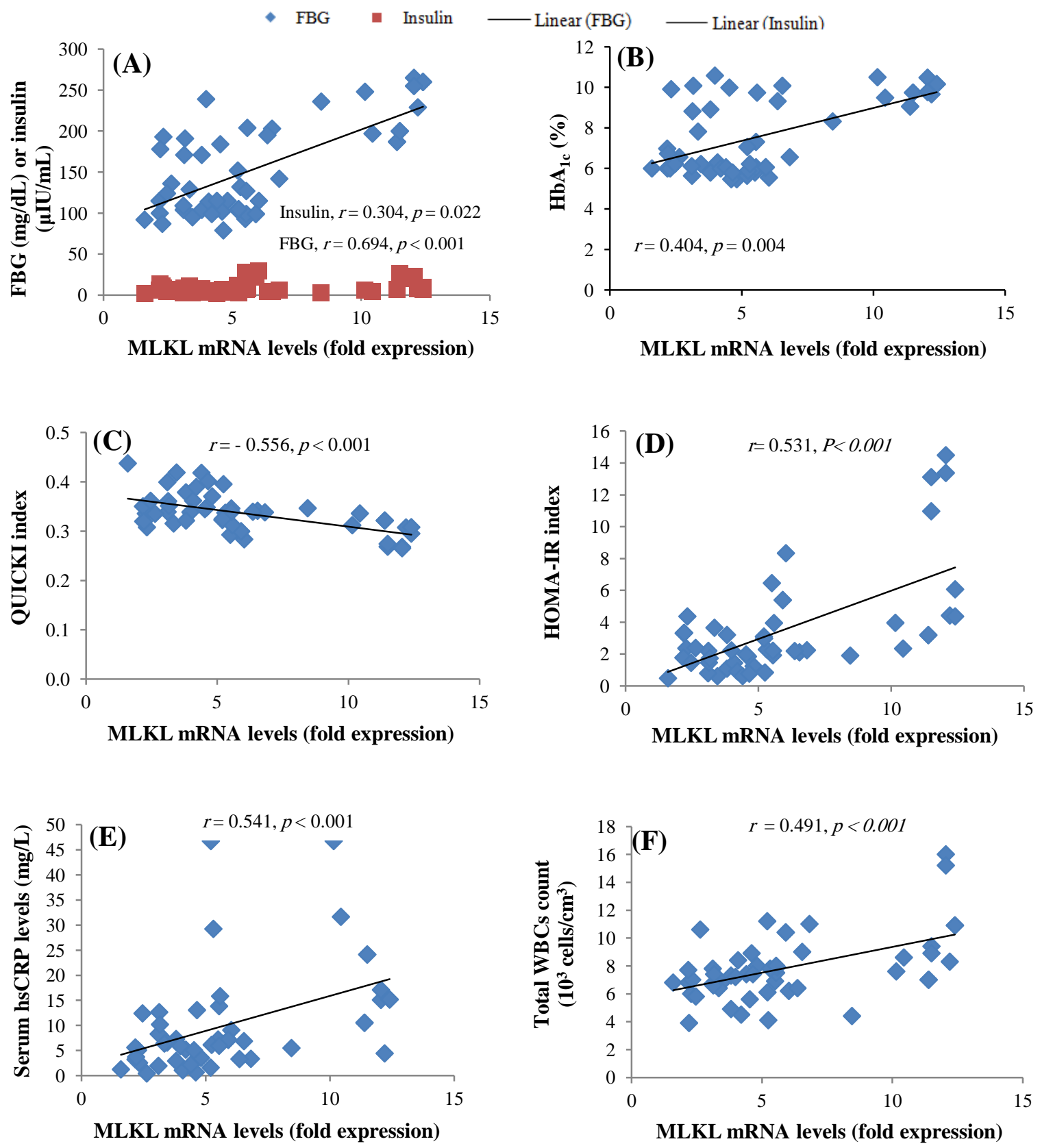

Fig. 4. Correlation between MLKL gene expression levels and other biochemical parameters (A) FBG and insulin levels, (B) HbA1c\%, (C) QUICKI index, (D) HOMA-IR index, (E) hsCRP levels, and (F) total WBCs count. 
Table 3. Predicting factors for severity of CAD

\begin{tabular}{lcc}
\hline Parameters & $\begin{array}{c}\boldsymbol{\beta} \\
\text { coefficient }\end{array}$ & $\begin{array}{c}\boldsymbol{p} \\
\text { value }\end{array}$ \\
\hline Model 1: $\mathbf{R}^{2}=\mathbf{3 6 . 6 \%}$ & & \\
Age & -0.147 & 0.218 \\
Gender & 0.071 & 0.549 \\
MLKL gene expression levels & 0.594 & $<0.001$ \\
& & \\
Model 2: $\mathbf{R}^{2}=\mathbf{4 3 . 5 \%}$ & & \\
Age & -0.262 & 0.162 \\
Gender & 0.099 & 0.424 \\
BMI & -0.082 & 0.572 \\
DM & 0.108 & 0.388 \\
Hypertension & 0.174 & 0.163 \\
Current smoking & -0.194 & 0.166 \\
MLKL gene expression levels & 0.630 & $<0.001$ \\
& & \\
Model 3: $\mathbf{R}^{2}=\mathbf{4 9 . 5 \%}$ & & \\
Age & -0.089 & 0.562 \\
Gender & 0.091 & 0.444 \\
BMI & -0.071 & 0.609 \\
DM & 0.033 & 0.788 \\
Hypertension & 0.164 & 0.170 \\
Current smoking & -0.156 & 0.245 \\
hsCRP & 0.360 & 0.032 \\
MLKL gene expression levels & 0.438 & 0.010 \\
\hline
\end{tabular}

signaling via controlling insulin-stimulated AKT phosphorylation pathway, in an inflammationindependent mechanism. Besides, regression analysis recognized BMI as a positive modulator for MLKL expression. This outcome declares the possible role of MLKL as a key mediator of saturated free fatty acids signaling in obesity-related insulin resistance and subsequent activation of cJun NH2-terminal kinase ${ }^{[39]}$. Increased hepatic MLKL levels have also been reported in obese diabetic mice ${ }^{[20]}$. The current study demonstrated that MLKL expression elevated in patients having BMI $\geq 25 \mathrm{~kg} / \mathrm{m}^{2}$ than those having BMI less than $25 \mathrm{~kg} / \mathrm{m}^{2}$. This observation highlights the link between MLKL and obesity, the primary risk factor for the Type 2 DM.

Necroptosis and inflammation are strongly connected. Necroptosis is recognized as a potent proinflammatory type of cell death as it could participate in the augmentation and chronicity of inflammation. Many cytokines produced during the immune response are robust cell death inducers ${ }^{[13,40]}$. It has been found that both necroptosis and inflammation could be avoided by RIPK3 and/or MLKL reduction ${ }^{[21,40]}$. Cumulative studies have shown the crucial function of necroptosis in inflammation and its implication in the pathogenesis of many inflammatory diseases $^{[6,13]}$. For this reason, MLKL gene expression level could be predicted by the level of some inflammation markers. We demonstrated that MLKL gene expression had strongly positive correlation with chronic inflammatory markers (hsCRP and WBCs count), which supports its proinflammatory role in atherosclerosis. This relation is also supported by multivariate regression analysis that identified both hsCRP and total WBCs count as predicting factors affecting mRNA levels of MLKL. It is important to mention that chronic inflammation could indirectly explain the link between MLKL and BMI, a marker of obesity, because of known association between obesity and chronic low-grade inflammation ${ }^{[41]}$. The current study also evaluated the diagnostic value of MLKL gene expression using ROC analysis. It has been found that MLKL is an excellent diagnostic value for discrimination between CVD patients and controls and a moderate diagnostic value for differentiation between diabetic and non-diabetic CVD patients. Therefore, we could assume that MLKL expression might be a promising diagnostic biomarker for CVD patients. Interestingly, we demonstrated that MLKL gene expression was significantly higher in patients having four atherosclerotic arteries as compared to patients having three atherosclerotic arteries. Moreover, regression analysis revealed that both hsCRP and MLKL gene expression levels were positive predictors for the CAD severity. Hence, further studies may be required to address the possible diagnostic value of MLKL as a marker for CAD severity. Based on these findings, we recommend that more effort should be devoted towards developing MLKL inhibitors targeting the necroptotic machinery, which might be a radical treatment for many CVD including atherosclerosis.

Based on our knowledge, this is an initial work to assess circulating MLKL gene expression in human atherosclerotic patients with the impact of type $2 \mathrm{DM}$. Overexpression of MLKL in atherosclerosis is correlated with the hallmarks of atherosclerosis such as dyslipidemia, inflammation, and insulin resistance. Furthermore, MLKL is an independent predictor of CAD severity. Therefore, the inclusion of MLKL inhibitors might provide a novel therapeutic hope for atherosclerotic patients.

\section{ACKNOWLEDGEMENTS}

This research received no grant from any funding agency in the public, commercial, or not-for-profit sectors.

CONFLICT OF INTEREST. None declared. 


\section{REFERENCES}

1. Libby P, Ridker PM, Hansson GK. Inflammation in atherosclerosis: from pathophysiology to practice. Journals of the american college of cardiology 2009; 54(23): 2129-2138.

2. Shaw JE, Sicree RA, Zimmet PZ. Global estimates of the prevalence of diabetes for 2010 and 2030. Diabetes research and clinical practice 2010; 87(1): 4-14.

3. Preis SR, Hwang SJ, Coady S, Pencina MJ, D’Agostino RB, Savage PJ, Levy D, Fox CS. Trends in all-cause and cardiovascular disease mortality among women and men with and without diabetes mellitus in the framingham Heart Study 1950 to 2005. Circulation 2009; 119(13): 1728-1735.

4. Huang WC, Sala-Newby GB, Susana A, Johnson JL, Newby AC. Classical macrophage activation upregulates several matrix metalloproteinases through mitogen activated protein kinases and nuclear factor- $\kappa \mathrm{B}$. PLoS one 2012; 7(8): e42507.

5. Schaub N, Reichlin T, Meune C, Twerenbold R, Haaf P, Hochholzer W, Niederhauser N, Bosshard P, Stelzig C, Freese M, Reiter M, Gea J, Buser A, Mebazaa A, Osswald S, Mueller C. Markers of plaque instability in the early diagnosis and risk stratification of acute myocardial infarction. Clinical chemistry 2012; 58(1): 246-256.

6. Pasparakis M, Vandenabeele P. Necroptosis and its role in inflammation. Nature 2015; 517(7534): 311-320.

7. Mallat Z, Taleb S, Ait-Oufella H, Tedgui A. The role of adaptive $\mathrm{T}$ cell immunity in atherosclerosis. Journal of lipid research 2009; 50: S364-369.

8. Lockshin RA, Williams CM. Programmed cell death-I. Cytology of degeneration in the intersegmental muscles of the pernyi silkmoth. Journal of insect physiology 1965; 11: 123-133.

9. Frank D, Vince JE. Pyroptosis versus necroptosis: similarities, differences, and crosstalk. Cell death and differentiation 2019; 26(1): 99-114.

10. Choi ME, Price DR, Ryter SW, Choi AMK. Necroptosis: A crucial pathogenic mediator of human disease. Journal of clinical investigation insight 2019; 4(15): e128834.

11. Holler N, Zaru R, Micheau O, Thome M, Attinger A, Valitutti S, Bodmer JL, Schneider P, Seed B, Tschopp J. Fas triggers an alternative, caspase-8-independent cell death pathway using the kinase RIP as effector molecule. Nature immunology 2000; 1(6): 489-495.

12. Degterev A, Huang Z, Boyce M, Li Y, Jagtap P, Mizushima N, Cuny GD, Mitchison TJ, Moskowitz MA, Yuan J. Chemical inhibitor of nonapoptotic cell death with therapeutic potential for ischemic brain injury. Nature chemical biology 2005; 1(2): 112-119.

13. Weinlich R, Oberst A, Beere HM, Green DR. Necroptosis in development, inflammation and disease. Nature reviews molecular cell biology 2017; 18(2): 127136.

14. Sun L, Wang H, Wang Z, He S, Chen S, Liao D, Wang L, Yan J, Liu W, Lei X, Wang X. Mixed lineage kinase domain-like protein mediates necrosis signaling downstream of RIP3 kinase. Cell 2012; 148(1-2): 21327.

15. Wallach D, Kang T-B, Dillon CP, Green DR. Programmed necrosis in inflammation: Toward identification of the effector molecules. Science 2016; 352(6281): aaf2154.

16. Dondelinger Y, Declercq W, Montessuit S, Roelandt R, Goncalves A, Bruggeman I, Hulpiau P, Weber K, Sehon CA, Marquis RW, Bertin J, Gough PJ, Savvides S, Martinou JC, Bertrand MJM, Vandenabeele P. MLKL compromises plasma membrane integrity by binding to phosphatidylinositol phosphates. Cell reports 2014; 7(4): 971-981.

17. Kaczmarek A, Vandenabeele P, Krysko D V. Necroptosis: The release of damage-associated molecular patterns and its physiological relevance. Immunity 2013; 38(2): 209-223

18. Chen X, Li W, Ren J, Huang D, He WT, Song Y, Yang C, Li W, Zheng X, Chen P, Han J. Translocation of mixed lineage kinase domain-like protein to plasma membrane leads to necrotic cell death. Cell research 2014; 24(1): 105-121.

19. Newton K, Dugger DL, Wickliffe KE, Kapoor N, De Almagro MC, Vucic D, Komuves L, Ferrando RE, French DM, Webster J, Roose-Girma M, Warming S, Dixit VM. Activity of protein kinase RIPK3 determines whether cells die by necroptosis or apoptosis. Science 2014; 343(6177): 1357-1360.

20. Xu H, Du X, Liu G, Huang S, Du W, Zou S, Tang D, Fan C, Xie Y, Wei Y, Tian Y, Fu X. The pseudokinase MLKL regulates hepatic insulin sensitivity independently of inflammation. Molecular metabolism 2019; 23: 14-23.

21. Newton K, Dugger DL,Maltzman A, Greve JM, Hedehus M, Martin-Mcnulty B, Carano RAD, Cao TC, VanBruggen N, Bernstein L, Lee WP, Wu X, Devoss J, Zhang J, Jeet S, Peng I,McKenzie BS, Roose-Girma M, Caplazi P, Diehl L, Webster JD, Vucic D. RIPK3 deficiency or catalytically inactive RIPK1 provides greater benefit than MLKLdeficiency in mouse models of inflammation and tissue injury. Cell dath and differentiation 2016; 23(9): 1565-76.

22. Karunakaran D, Geoffrion M, Wei L, Gan W, Richards L, Shangari P, DeKemp EM, Beanlands RA, Perisic L, Maegdefessel L, Hedin U, Sad S, Guo L, Kolodgie FD, Virmani R, Ruddy T, Rayner KJ. Targeting macrophage necroptosis for therapeutic and diagnostic interventions in atherosclerosis. Science advances 2016; 2(7): e1600224.

23. Rasheed A, Robichaud S, Nguyen M-A, Geoffrion M, Wyatt H, Cottee ML, Dennison T, Pietrangelo A, Lee R, Lagace TA. Loss of MLKL (mixed lineage kinase domain-like protein) decreases necrotic core but increases macrophage lipid accumulation in atherosclerosis. Arteriosclerosis, thrombosis, and vascular biology 2020; 40(5): 1155-1167.

24. Günther C, He GW, Kremer AE, Murphy JM, Petrie EJ, Amann K, Vandenabeele P, Linkermann A, Poremba C, Schleicher U, Dewitz C, Krautwald S, Neurath MF, Becker C, Wirtz S. The pseudokinase MLKL mediates 
programmed hepatocellular necrosis independently of RIPK3 during hepatitis. Journal of clinical investigation 2016; 126(11): 4346-4360.

25. Matthews DR, Hosker JP, Rudenski AS, Naylor BA, Treacher DF, Turner RC. Homeostasis model assessment: insulin resistance and $\beta$-cell function from fasting plasma glucose and insulin concentrations in man. Diabetologia 1985; 28(7): 412-419.

26. Katz A, Nambi SS, Mather K, Baron AD, Follmann DA, Sullivan G, Quon MJ. Quantitative insulin sensitivity check index: A simple, accurate method for assessing insulin sensitivity in humans. Journal of clinical endocrinology and metabolism 2000; 85(7): 2402-2410.

27. Livak KJ, Schmittgen TD. Analysis of relative gene expression data using real-time quantitative PCR and the 2- $\Delta \Delta$ CT method. Methods 2001; 25(4): 402-408.

28. World Medical Association (WMA) Declaration of Helsinki-Ethical Principles for Medical Research involving human subjects. 64th WMA General Assembly, Fortaleza, Brazil, October 2013. Reterieved from: https://tinyurl.com/y7f5boyg.

29. Grundy SM, Benjamin IJ, Burke GL, Chait A, Eckel RH, Howard B V., Mitch W, Smith SC, Sowers JR. Diabetes and cardiovascular disease: A statement for healthcare professionals from the american heart association. Circulation 1999; 100(10): 1134-1146.

30. Sanad EF, Hamdy NM, El-Etriby AK, Sebak SA, ElMesallamy HO. Peripheral leucocytes and tissue gene expression of granzyme B/perforin system and serpinB9: Impact on inflammation and insulin resistance in coronary atherosclerosis. Diabetes research and clinical practice 2017; 131:132-141.

31. Gupta K, Phan N, Wang Q, Liu B. Necroptosis in cardiovascular disease - a new therapeutic target. Journal of molecular and cellular cardiology 2018; 118: 26-35.

32. Wang Q, Liu Z, Ren J, Morgan S, Assa C, Liu B. Receptor-interacting protein kinase 3 contributes to abdominal aortic aneurysms via smooth muscle cell necrosis and inflammation. Circulation research 2015; 116(4): 600-611.

33. Lin J, Li H, Yang M, Ren J, Huang Z, Han F, Huang J, Ma J, Zhang D, Zhang Z, Wu J, Huang D, Qiao M, Jin G, Wu Q, Huang Y, Du J, Han J. A role of RIP3mediated macrophage necrosis in atherosclerosis development. Cell reports 2013; 3(1): 200-210.

34. Tsuruta R, Fujita M, Ono T, Koda Y, Koga Y, Yamamoto T, Nanba M, Shitara M, Kasaoka S, Maruyama I, Yuasa M, Maekawa T. Hyperglycemia enhances excessive superoxide anion radical generation, oxidative stress, early inflammation, and endothelial injury in forebrain ischemia/reperfusion rats. Brain research 2010; 1309: 155-163.

35. LaRocca TJ, Sosunov SA, Shakerley NL, Ten VS, Ratner AJ. Hyperglycemic conditions prime cells for RIP1-dependent necroptosis. Journal of biological chemistry 2016; 291(26): 13753-13761.

36. Meerwaldt R, Links T, Zeebregts C, Tio R, Hillebrands J-L, Smit A. The clinical relevance of assessing advanced glycation endproducts accumulation in diabetes. Cardiovascular diabetology 2008; 7(1): 29.

37. Karrowni W, Li Y, Jones PG, Cresci S, Abdallah MS, Lanfear DE, Maddox TM, McGuire DK, Spertus JA, Horwitz PA. Insulin resistance is associated with significant clinical atherosclerosis in nondiabetic patients with acute myocardial infarction. Arteriosclerosis, thrombosis, and vascular biology 2013; 33(9): 2245-2251.

38. Festa A, D'Agostino Jr R, Howard G, Mykkänen L, Tracy RP, Haffner SM. Chronic subclinical inflammation as part of the insulin resistance syndrome: the Insulin Resistance Atherosclerosis Study (IRAS). Circulation 2000; 102(1): 42-47.

39. Kant S, Barrett T, Vertii A, Noh YH, Jung DY, Kim JK, Davis RJ. Role of the mixed-lineage protein kinase pathway in the metabolic stress response to obesity. Cell reports $2013 ; 4(4)$ : 681-688.

40. Welz PS, Wullaert A, Vlantis K, Kondylis V, Fernández-Majada V, Ermolaeva M, Kirsch P, SternerKock A, Van Loo G, Pasparakis M. FADD prevents RIP3-mediated epithelial cell necrosis and chronic intestinal inflammation. Nature 2011; 477(7364): 330334.

41. Stępień M, Stępień A, Wlazeł RN, Paradowski M, Banach M, Rysz J. Obesity indices and inflammatory markers in obese non-diabetic normo- and hypertensive patients: A comparative pilot study. Lipids in health disease 2014; 13: 29. 